\title{
Chapter 3 \\ Climate Change Adaptation Practices \\ Towards Sustainable Watershed \\ Management: The Case of Abuan \\ Watershed in Ilagan City, Philippines
}

\author{
Orlando F. Balderama
}

\section{Abbreviations}

$\begin{array}{ll}\text { AIWMP } & \text { Abuan Integrated Watershed Management Project } \\ \text { ASTI } & \text { Advance Science and Technology Institute } \\ \text { CBMS } & \text { Community-Based Management System } \\ \text { LGU } & \text { Local Government Unit } \\ \text { CCA } & \text { Climate Change Adaptation } \\ \text { CDP } & \text { Comprehensive Development Plan } \\ \text { CLUP } & \text { Comprehensive Land Use Plan } \\ \text { DILG } & \text { Department of Local Government } \\ \text { DREAM } & \text { Disaster Risk and Exposure Assessment for Mitigation Project } \\ \text { DRRM } & \text { Disaster Risk Reduction and Management } \\ \text { DRRMO } & \text { Disaster Risk Reduction and Management Office } \\ \text { DSSAT } & \text { Decision Support System for Agro-Technology Transfer } \\ \text { FDSS } & \text { Farmer Decision Support System } \\ \text { IBM } & \text { International Business Machines } \\ \text { ICT } & \text { Information and Communication Technology } \\ \text { IRR } & \text { Implementing Rules and Regulation } \\ \text { LCCAP } & \text { Local Climate Change Action Plans } \\ \text { LDRRMC } & \text { Local Disaster Risk and Reduction Management Council } \\ \text { LGC } & \text { Local Government Code } \\ \text { NOAH } & \text { Nationwide Operational Assessment of Hazards Project } \\ \text { RA } & \text { Republic Act } \\ \text { SMS } & \text { Short Messaging System } \\ & \end{array}$

O. F. Balderama $(\bowtie)$

College of Engineering, Isabela State University, Isabela, Philippines

e-mail: orlando.f.balderama@isu.edu.ph

T. Ito et al. (eds.), Interlocal Adaptations to Climate Change in East and Southeast Asia, SpringerBriefs in Climate Studies,

https://doi.org/10.1007/978-3-030-81207-2_3 


\subsection{Introduction}

In the Philippines, it is the local government units (LGUs) who are at the forefront in implementing initiatives related to disaster risk reduction and management (DRRM) and climate change adaptation (CCA) in their respective jurisdictions. The legal framework governing DRRM and CCA devolves to the LGUs the responsibility to prepare and integrate local CCA and DRRM into locally mandated plans, particularly into the Comprehensive Land Use Plan (CLUP) and Comprehensive Development Plans (CDP). The legal framework governing the country's climate change and disaster risk reduction and management policies are as follows:

(a) The Local Government Code (LGC) of 1991 (Republic Act [RA] No. 7160). The LGC devolves to LGUs the responsibility of delivering basic services in agriculture, health, environment, and social services to the local constituents. The Act mandates each LGU to prepare their CDP and CLUP.

(b) The Climate Change Act of 2010 (RA 9729) and its Implementing Rules and Regulations (IRR) (Administrative Order 2010-01). The Act acknowledges the Philippines' vulnerability to climate change and the need for appropriate adaptation. This Act creates a comprehensive framework for systematically integrating climate change and disaster risk reduction (DRR) into various phases of policy formulation, development plans, poverty reduction strategies, and other development tools and techniques. The Act establishes the Climate Change Commission as the sole policymaking body to prepare a National Climate Change Framework, National Climate Change Action Plan, and guidelines for the preparation of local climate change action plans (LCCAP).

(c) Disaster Risk Reduction and Management Act of 2010 (RA 10121) and IRR. Section 11 (b)(2) of the Act mandates the Local Disaster Risk and Reduction Management Council (LDRRMC) to ensure that DRR and CCA are integrated into local development plans, programs, and budgets as a strategy in sustainable development and poverty reduction. This provision integrates DRRM and CCA into physical and land-use planning, budget, infrastructure, education, health, environment, housing, and other sectors. The law requires LGUs to set aside 5\% of their regular revenues for DRRM.

This chapter discusses highlights and lessons learned from the Abuan Integrated Watershed Management Project (AIWMP), a five-year program funded by the United States Agency for International Development-Philippines, which focused on the implementation of bottom-up, self-initiated CCA strategies in the watershed. The initiated measures have led to policy outcomes that have enhanced the resiliency of communities and watershed ecosystems against natural disasters and climate change. In addition, the activities, institutional arrangements, and policy outcomes are also discussed. Innovations in the use of information communication technology (ICT), mobile technologies, and remote sensing offer opportunities to modernize the agriculture sector; however, barriers to upscaling require the establishment of an enabling policy environment and capacity building in order to extend the potential application of these technologies. 


\subsection{Project Setting: Climate Outlook, Ilagan City and the Abuan Watershed}

Isabela province in the Cagayan Valley is the Philippines' top corn producer. Ilagan City in the province of Isabela has the biggest land area under corn and is regarded as the Corn Capital of the Philippines. Climate change poses long-term threats to the livelihoods of farmers and to national food security. According to the Philippine Atmospheric Geophysical and Astronomical Services Administration (2011), the country's weather bureau, the 2050 scenario in Isabela will result in a $1.9{ }^{\circ} \mathrm{C}-2.1^{\circ} \mathrm{C}$ increase in temperature, a $29 \%$ decrease in mean rainfall in the dry months, and a $1.7 \%-25.1 \%$ increase in rainfall in the wet months. This will translate to frequent and more intense flooding and dry spell events, resulting in recurring crop damage and worsening poverty.

The increasing frequency of inter-annual anomalies from both typhoons and droughts in recent years foretell the impacts of global warming. In the early half of 2010, prolonged dry spells in the Philippines caused rice and corn crops to wilt. In November of the same year, Typhoon Juan hit Isabela Province, inflicting Philippines Peso (PHP) 542 million in damages on Ilagan City, with $45 \%$ of the total damages attributed to the agricultural sector. The following year, Typhoon Quiel slammed Isabela, causing PHP 115 million in damages, and displacing more than 500,000 people (NDRRMC 2011). In the Abuan floodplain, some 2342 residents from seven barangays (villages) were evacuated and were housed in temporary shelters due to the flooding of those communities (DRRMO, City Government of Ilagan (NDRRMC 2011).

Ilagan City lies at the confluence of the Cagayan and Ilagan rivers. It has a population of 33,000 households in 91 barangays, with majority of the residents being corn and rice farmers. The economic base of the city is agriculture, with 28,000 hectares (ha) of cornland and 7000 ha of rice land. Other crops planted are sugar cane, tobacco, and cassava. On the eastern barangays of the city lies the Abuan watershed, a 63,754 ha ecosystem that supports some 2900 farming households. The upper catchment has an area of 44,000 ha and is located in the Northern Sierra Madre Natural Park, which supports the last remaining old-growth dipterocarp forests in the country. The lower sub-catchments consist of farmlands, residual forests, and brushland, with an area of 19,000 ha (or 31\%) of the watershed area. The watershed is named after the Abuan River, which, together with the smaller Bintacan River, drains into the Ilagan River before merging with the Cagayan River (Fig. 3.1). Flooding in the Abuan floodplain is triggered when flows are impeded when the Ilagan River and Cagayan River break their banks and inundate the delta. The figure shows the map of the Abuan watershed. The lower Abuan catchments (in yellow) consist of tenured lands with an area of 4057 ha. 


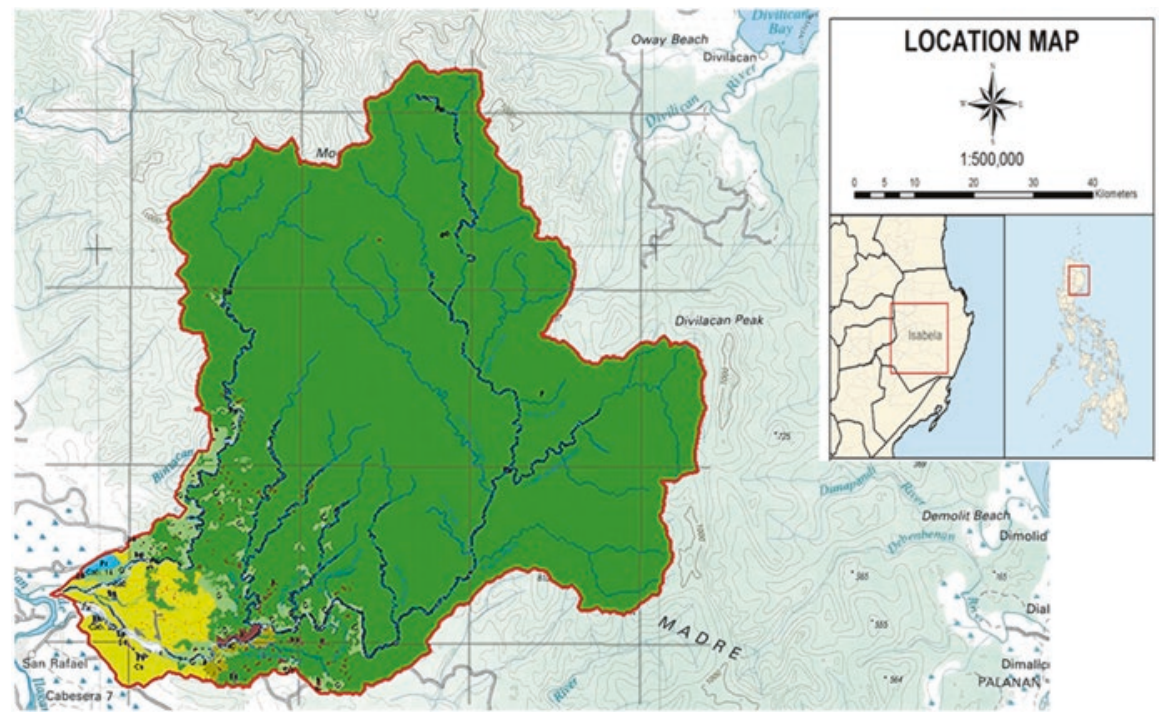

Fig. 3.1 Map of study area

\subsection{Implementation Strategies and Activities}

Recognizing the importance of LGUs under a devolved setup, the AIWMP worked at three levels to produce policy outcomes for CCA and DRRM in the City of Ilagan:

(a) The AIWMP implemented innovative activities at the barangay level through the Barangay DRRM councils in coordination with City DRRMO. The AIWMP trained barangay and city officials on the use of tools and state-of-the-art technologies, i.e. GIS maps, crop models, weather and flood sensors as decision support system for farmers and government.

(b) The city government officials, convinced of the effectiveness of the demonstration activities in the pilot barangays, became interested in the widespread use of these new tools and practices to other city areas.

(c) The AIWMP assisted the LGU in DRRM and CCA policy and made preparations as required by the law. Light Detection and Raging (LIDAR) maps and Community-Based Monitoring Systems (CBMS) were made available to local residents, which allowed the AIWMP to demonstrate their findings to DRRM and CCA policy formulation, and to subsequently integrate them into the LCCAP of the city. 


\subsubsection{Flood Risk Mitigation Activities}

\subsubsection{Installation of Automated Weather Stations}

The project installed rain gauges and water-level sensors at bridges along the Abuan River and Bintacan River as part of establishing an Early Flood Warning Systems. A Memorandum of Agreement (MOA) with the Department of Science and Technology (DOST) enabled the project team to include these stations in Project NOAH (Nationwide Operational Assessment of Hazards), the Philippine's flagship program on disaster prevention and mitigation, and to be allowed access to data from its eastern stations in Isabela, where most storms originate. The contribution of the Ilagan River to flooding in the Abuan floodplain is considerable.

\subsubsection{Topographic Mapping and Flood Simulation}

The project completed topographic and bathymetric surveys using unmanned aerial vehicles (UAVs). A digital elevation model and hydrologic data were produced and inputted into a hydrologic model to simulate flooding in the Abuan floodplain. Flood inundation maps for 5-, 25-, and 100-year storm return periods were produced. Figure 3.2 shows a 100-year return period. Flood depths of $2.5 \mathrm{~m}$ (red areas) were found to overlap with human settlements threatening households. Flood models were generated using HEC-HMS, HEC-RAS and ARC-INFO.
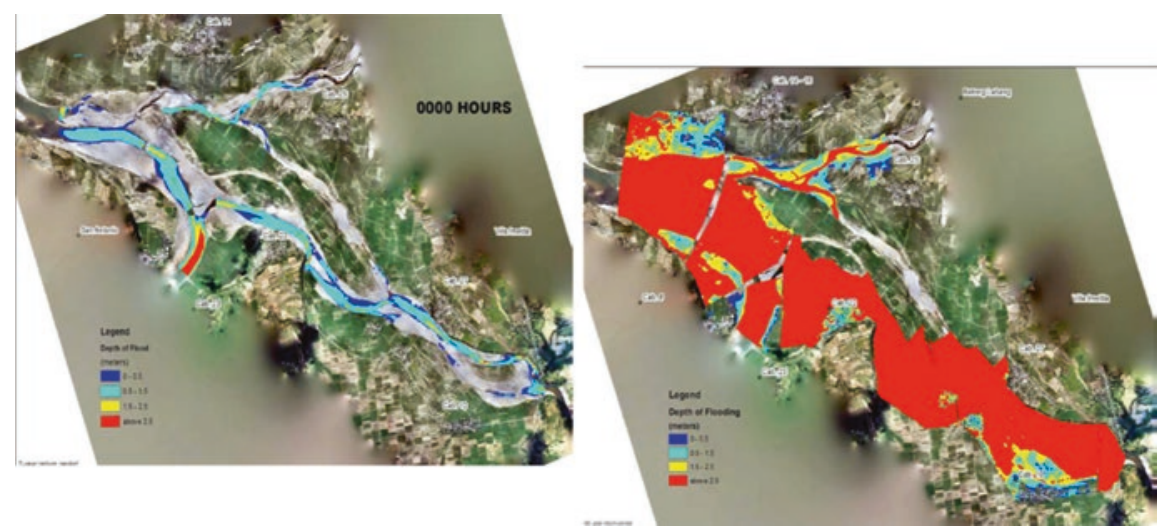

Fig. 3.2 Development of flood maps: before-and-after flood risk map of Abuan flood plain 


\subsubsection{Vulnerability Mapping and BDRRM Planning}

Use of digital spatial mapping was introduced to analyze climate hazard vulnerabilities in community study areas. The flood inundation maps that had been produced were presented in Abuan barangays for community validation. This was followed by barangay training and planning workshops. Through the barangay focus group discussions, the vulnerable groups (i.e., flood-prone sitios,${ }^{1}$ elderly, persons with disabilities, women, and children) were identified by the community. Accordingly, barangay plans were prepared, which included the establishment of early warning systems (EWS), evacuation sites and camp management plans. The community also identified schools and covered courts as future evacuation centers. Should these places prove to be unfeasible, the barangay LGU identified elevated areas that could be used as temporary staging areas.

\subsubsection{EWS}

The City DRRMO established coordination protocols for barangay officials in issuing typhoon warnings to residents. As part of the established EWS, barangay officials are now using SMS, two-way radios, light-emitting diodes boards, and megaphones to issue alerts. Following the practice in the province, forced evacuation is also being implemented in flood-prone barangays whenever a typhoon enters Isabela. In a typhoon alert, the City DRRMO monitors the rainfall and water level readings via internet (www.fmon.asti.dost.gov.ph). The limitation of this service, however, is it depends on power and an internet connection, which may not function during a typhoon.

\subsubsection{Drought Risk Mitigation Activities}

\subsubsection{Crop Modelling for Corn Production and Climate Change Impact Assessment}

Crop models enable scientists to understand and to predict crop responses to global warming, as indicated by increasing $\mathrm{CO}_{2}$, temperatures, and water scarcity. Accordingly, the project installed an agro-meteorological station and soil moisture sensors in the Abuan watershed to record rainfall, temperature, and other parameters. Two crop models (i.e., Decision Support System for Agri-Technological Transfer [DSSATT] and AquaCrop) were calibrated and validated within reasonable accuracy during two cropping seasons (Tongson et al. 2017; Balderama et al. 2017). The crop model simulated the impacts of climate change on biomass and yield. The model can also simulate present impacts, which can provide valuable

${ }^{1}$ A sitio is a territorial enclave that forms part of a barangay. 
insights for farmers and help them to make informed decisions regarding the dayto-day activities on their farms.

\subsubsection{Text Messages of Daily Weather Forecasts}

The DSSAT crop model was automated to generate weather and crop advisories to farmers via SMS. Daily weather forecasts were made available using a numerical weather forecasting model called Weather Information-Integration for System Enhancement (WISE), which was developed by IBM Philippines and the Institute of Environmental Science and Meteorology (IESM) of the University of Philippines under Project NOAH. These daily forecasts can be viewed on the internet (www. weather-manila.com) or at the Project NOAH website.

The proof of concept for the weather and crop advisories was developed in 2016-2017 (Trogo et al. 2015a, b; Ebardaloza et al. 2015). The system was then tested to a pilot group of 30 farmers using GSM cellular phones. Each of the pilot farmers was given a prepaid SIM card, and was tasked to enroll their farms, send SMS queries, and receive replies from the system. The system can respond to queries about daily rainfall, amount of fertilizers required, best planting dates, yields, etc. The system then processes each query using these parameters, and responds to the farmer. The SMS queries were tallied and categorized during the pilot implementation. Almost all of the queries tallied were about rainfall forecasts, indicating the importance of this parameter to farmers. The list expanded to more than 1000 farmers as the LGU enrolled more farmers to receive text messages from the system.

\subsubsection{Policy-Level Activities}

\subsubsection{Vulnerability Assessments and Mapping}

The DILG introduced the CBMS as a tool that LGUs can use to target households, for bottom-up planning, and budgeting (DILG-MC 2014). Accordingly, the CBMS of Ilagan City consists of a database of 33,000 geo-tagged households and includes indicators relating to income, education, housing, access to basic services, water, sanitation, flood risks, etc. that are generated at the household and individual levels.

The city government then obtained copies of high-resolution $(0.5 \mathrm{~m})$ LIDAR maps and flood inundation maps from the Disaster Risk and Exposure Assessment for Mitigation (DREAM) Project of the DOST. The AIWMP overlaid flood inundation maps (Fig. 3.3) with CBMS household maps to generate maps of vulnerable households (i.e., low income, lacking access to safe water, lacking access to toilets, people living in makeshift shelters, and people with informal tenure), and maps of corn and rice growing areas. Figure 3.4 shows a vulnerability map of central Ilagan City overlain with households classified as poor and not poor. 


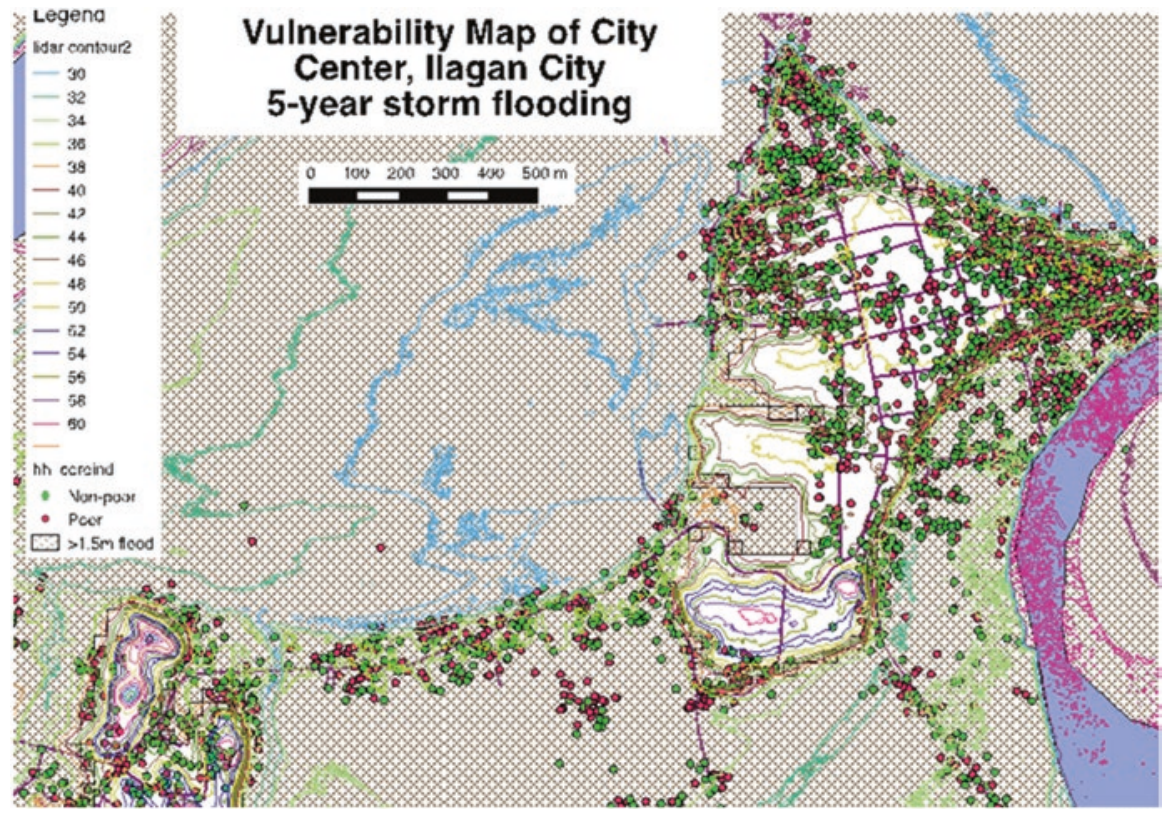

Fig. 3.3 Flood vulnerability map of central Ilagan City

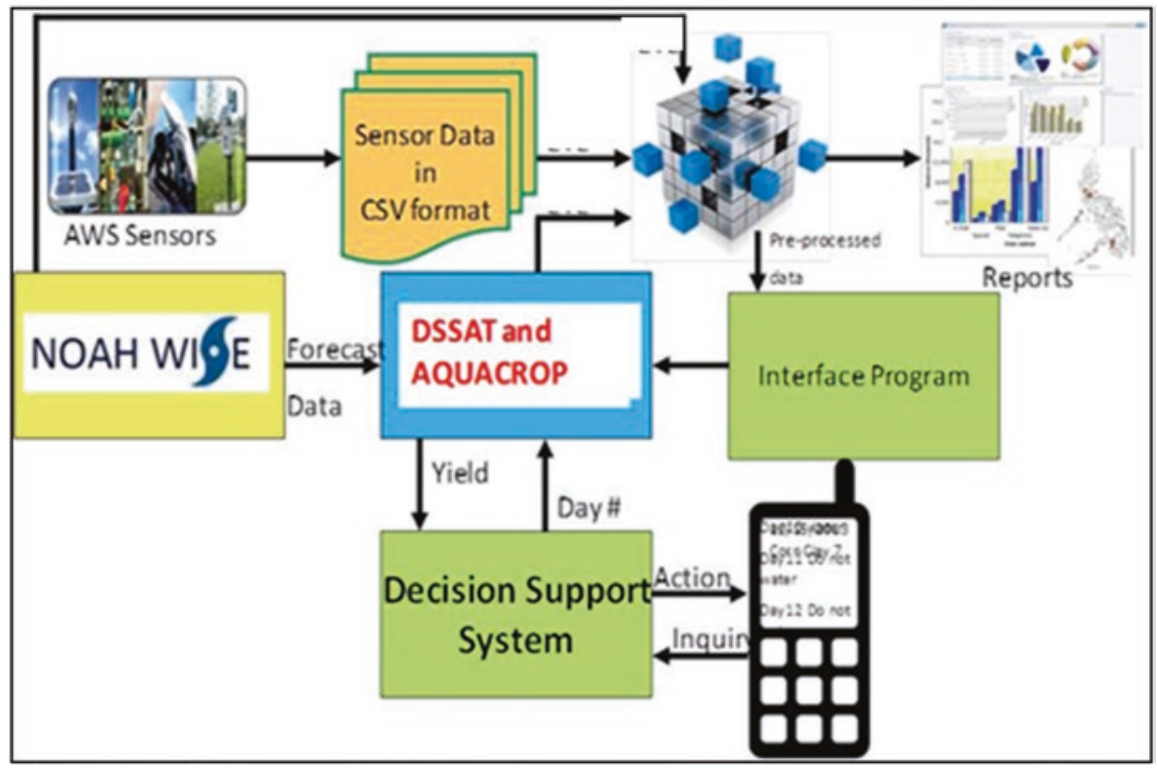

Fig. 3.4 Architecture design of decision support system 


\subsubsection{Downscaling Global Circulation Models and Impact Modelling}

Assessing the impacts of climate change primarily requires understanding past trends in local climate (baseline) and projecting future trends based on best-fitting climate models. Secondly, climate projections are assessed against possible impacts on agriculture, water supplies, and health. This requires expertise in performing impact assessments for particular sectors of interest. In this case story, impact assessments were produced for corn and water resources.

The CSIRO-k3 (Commonwealth Scientific and Industrial Research Organization) GCM (Global Circulation Model) (Gordon et al. 2002) was selected to generate climate projections for 2050s and 2090s for Ilagan City. Daily weather files were generated using the MarkSim weather generator, and the data were inputted into crop models (Jones and Thornton 2000). The projected climates for 2050s and 2090s were used to simulate corn production (Tongson et al. 2017) and the changes to water resources in the Abuan watershed (Rojas 2017). Findings showed that corn yields would decrease up to $60 \%$, and water loss due to evaporation would increase up to $33 \%$, reducing the amount of water for economic uses.

\subsubsection{Formulation of LCCAP Chapter 2}

Chapter 2 of the LCCAP consists of climate projections, risk exposure of vulnerable groups to climate change and the corresponding policies to address them, adaptive capacity maps, and CCA programs and plans. The LCCAP was adopted by the LGU through a resolution passed by the City Council.

\subsubsection{Development of Farmers Decision Support System}

The Farmer Decision Support System (FDSS) is an ICT-enabled internet and SMS platform capable of advising individual farmers on how crops will respond given the climate forecast for the next cropping season. It is also a diagnostic tool that helps farmers to identify yield gaps and their sources. The model inputs are data from the climate seasonal forecast of the NOAH-WISE, five-day weather forecast from the Weather Data Solutions of IBM (IBM-WEDA), and actual daily weather from the weather stations of the Advanced Science and Technology Institute of the DOST (DOST-ASTI) (Trogo et al. 2015a, b). Based on inputs on weather, soil, and farmer practices, the platform simulates crop responses through the DSSAT crop model for corn (Balderama et al. 2017). The outputs of the model runs are crop calendar, biomass, and yields, which are sent by SMS or downloaded over the internet. 


\subsection{Lessons Learned}

1. The local agricultural landscape in Abuan watershed consists of a mosaic of smallholder farms characterized by high landscape variability and heterogeneity. This study provided a clear understanding of climate change, the El NiñoSouthern Oscillation, and increasing intensity of natural disasters that adds to the complexity of issues that are faced by small farmers. The other realities highlighted by this study are the ineffective agriculture extension services, which are constrained by lack of capacity and resources. Hence, these smallholder farmers are facing an uphill battle against poverty, degraded ecosystems, and worsening climate change.

2. From the project strategies implemented, the bottom-up demonstration activities and policy level activities resulted in the following policy outcomes:

(a) Development of Sangguniang Panlungsod Resolution (Provincial Council Resolution) No. 038. Resolution approving the climate change action plan of Ilagan City for CY 2017-2022. This provides an effective strategy for mainstreaming research and development outputs into policies that can be implemented by the local governments of the province.

(b) City Ordinance No. 117-2016. On a municipal level, an ordinance implementing flood evacuation drills in all flood-prone barangays in Ilagan City on a regular basis to increase the barangays' capacity and to ensure that the communities are prepared in cases of disasters and/or calamities. This activity can now be easily rolled-out to other localities, given a legal mandate and actual demonstration showcase.

3. Looking at the current legal framework used in the Philippines for CCA and DRRM, which has involved extensive stakeholder consultations, a suitable method has been found through which the legal framework can provide entry points for projects like AIWMP to embed its activities within the framework of LGU plans and programs. This study provided a good example of how to align and plan the interface of a project framework to involve local governments and facilitate the effective adaption among stakeholders.

4. It was also concluded that while technologies and innovations introduced by the project show great potential and offer opportunities for modernizing agriculture, farmers and city extension workers' knowledge of crop models, remote sensing, and their potential use in decision making are still rudimentary and still needs more field validations. This could be made part of future training programs and other future endeavors to improve and sustain initial success of the project

5. It was also determined that access to ICT is also expensive in rural areas, and thus constrains use of state-of-the-art technology. There is therefore a need for a national broadband policy and ICT investments in underserved areas. The pilot introduction of information and communication technologies-enabled (ICT- 
enabled) crop and weather advisories have demonstrated great promise for modernizing agriculture; however, such a feat would require an enabling policy environment in the ICT sector in order to stimulate growth and benefit the agriculture sector.

6. Another important lesson is mainstreaming of multidisciplinary approaches to CCA and DRRM drawing from natural, social, and ICT fields that were facilitated at the local level. Parallel interventions at the national level (involving the Department of Information and Communications Technology, Department of Agriculture, Department of Science and Technology, state universities and colleges, and the private sector) will require an enabling policy environment.

7. Finally, the AIWMP demonstrated use of innovative ICT-enabled technologies that can help to modernize the agricultural sector. Precision agriculture and individualized advice to farmers using remote sensing, SMS, and internet show great promise. However, there is a need for more capacity building among LGU agriculture workers in ICT and crop modeling. An enabling policy environment in the ICT sector will spur development in applications that benefit the agricultural sector and small farmers.

\section{References}

Balderama O, Alejo L, Tongson E, Pantola RR (2017) Development and application of corn model for climate change impact assessment and decision support system: enabling Philippine farmers to adapt to climate variability. In: Leahl Filho W (ed) Climate change research at universities. Hamburg University, Springer, pp 373-387

DILG-MC (Department of Interior and Local Government Memorandum Circular) 2014-135. Guidelines on the Formulation of Local Climate Change Action Plan (LCCAP). DILG. (21 October 2014)

Ebardaloza JBR, Trogo R, Sabido DJ, Tongson E, Bagtasa G, Balderama OF (2015) Enabling Philippine farmers to adapt to climate variability using seasonal climate and weather forecast with a crop simulation model in an SMS-based Farmer Decision Support System. Accessed 7 Oct 2017. http://adsabs.harvard.edu/abs/2015AGUFMGC53G1298E

Gordon HB, Rotstayn LD, McGregor JL, Dix MR, Kowalczyk EA, O'Farrell SP, Waterman LJ, Hirst AC, Wilson SG, Collier MA, Watterson IG, Elliot TI (2002). The CSIRO Mk3 Climate System Model. CSIRO Atmospheric Research Technical Paper No. 60. Aspendale. Commonwealth Scientific and Industrial Research Organisation, Victoria

Jones PG, Thornton PK (2000) MarkSim software to generate daily weather data for Latin America and Africa. Agron J 92(3):445-453

NDRRMC (National Disaster Risk Reduction and Management Council) (2011) NDRRMC SitRep No. 12: Effects of Typhoon 'QUIEL' (Nalgae). Accessed 4 April 2016. http://www. ndrrmc.gov.ph/attachments/article/1763/SitRep_No_12_effects_of_Typhoon_QUIEL_as_ of_10OCT2011_0600H.pdf

Philippine Atmospheric Geophysical and Astronomical Services Administration (2011) Climate projection for Isabel Province, Quezon City

Rojas D (2017) Hydrology of Abuan watershed. Internal Report to Worldwide Fund for Nature. Quezon City Philippines 
Tongson EE, Alejo L, Balderama OF (2017) Simulating impacts of El Niño and climate change on corn yield in Isabela, Philippines. Clim Disaster Dev J 2(1):29-39

Trogo R, Ebardaloza JB, Sabido DJ, Bagtasa G, Tongson E, Balderama OF (2015a) SMSBased Smarter Agriculture Decision Support System for Yellow Corn Farmers in Isabela. In: Proceedings of the 2015 IEEE Canada International Humanitarian Technology Conference (IHTC2015), 31 May 2015 to 4 June 2015, Ottawa, Canada. Ottawa, Canada: Institute of Electrical and Electronics Engineers

Trogo R, Ebardaloza JB, Sabido J, Tongson E, Bagtasav G, Balderama OF (2015b) Enabling Philippine farmers to adapt to climate variability using seasonal climate and weather forecast with a crop simulation model in an SMS-based Farmer Decision Support System. Paper presented at the 2015 AGU Fall Meeting, San Francisco, CA, 14-18 December 2015

Open Access This chapter is licensed under the terms of the Creative Commons Attribution 4.0 International License (http://creativecommons.org/licenses/by/4.0/), which permits use, sharing, adaptation, distribution and reproduction in any medium or format, as long as you give appropriate credit to the original author(s) and the source, provide a link to the Creative Commons license and indicate if changes were made.

The images or other third party material in this chapter are included in the chapter's Creative Commons license, unless indicated otherwise in a credit line to the material. If material is not included in the chapter's Creative Commons license and your intended use is not permitted by statutory regulation or exceeds the permitted use, you will need to obtain permission directly from the copyright holder. 